\title{
EUS-guided pseudocyst drainage as a one-step procedure using a novel multiple wire insertion technique
}

The aim of this report is to describe the technique of endoscopic ultrasound (EUS)-guided pseudocyst drainage as a one-step procedure using a novel multiple wire insertion technique facilitated by the double-lumen biliary cytology brush catheter (Cook Medical, Winston-Salem, North Carolina, USA).

Six symptomatic patients underwent EUS-guided pseudocyst drainage using the novel multiple wire insertion technique ( Video 1 ).

After ensuring that there was less than $1 \mathrm{~cm}$ distance between the gastric wall and the pseudocyst and excluding the presence of vasculature in the path of the needle by means of color Doppler ultrasonography, a 19-gauge needle as employed in fine-needle aspiration was used to puncture the pseudocyst under EUS guidance. A 0.035 -inch guide wire was then introduced through the needle and coiled inside the pseudocyst. Subsequently, the tract was sequentially dilated over the guide wire using an endoscopic retrograde cholangiopancreatography cannula and/or a Soehendra biliary dilator, followed by dilation with a CRE Wireguided Balloon Dilator (Boston Scientific, Natick, Massachusetts, USA). The balloon was then removed, leaving the guide wire coiled in the cyst. A double-lumen biliary cytology brush catheter was used to facilitate placement of multiple guide wires into the cyst cavity as follows. The brush was completely retracted and removed from the sheath. The device was thus modified into an $8-\mathrm{Fr}$ catheter with two lumens, each of which

\section{Video 1}

Endoscopic ultrasound (EUS)-guided pseudocyst drainage using a multiple wire insertion technique facilitated by the double-lumen biliary cytology brush catheter.

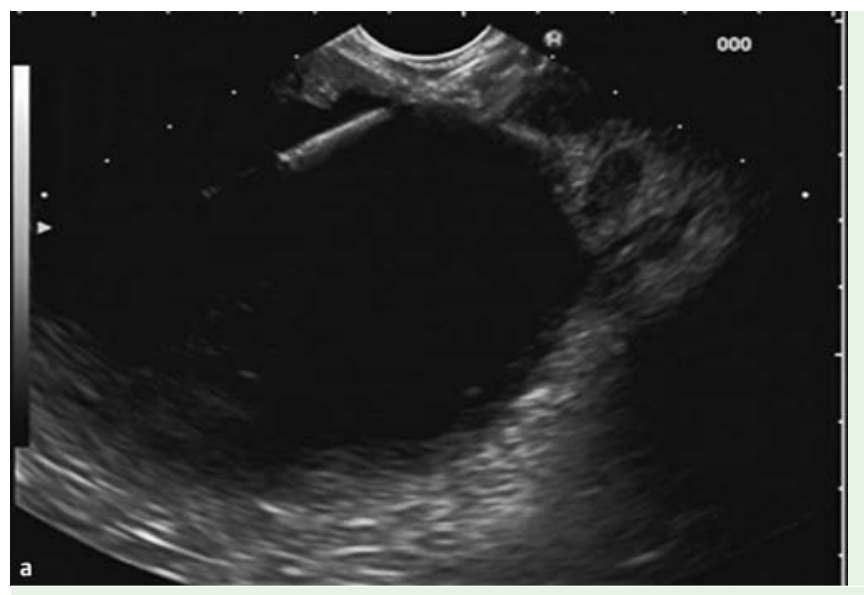

Fig. 1 Patient presented with a symptomatic pseudocyst and underwent endoscopic ultrasound (EUS)-guided drainage. a A 19-gauge fine-needle-aspiration needle was used to puncture the pseudocyst. Two wires were placed in the pseudocyst using a modified biliary brush catheter.

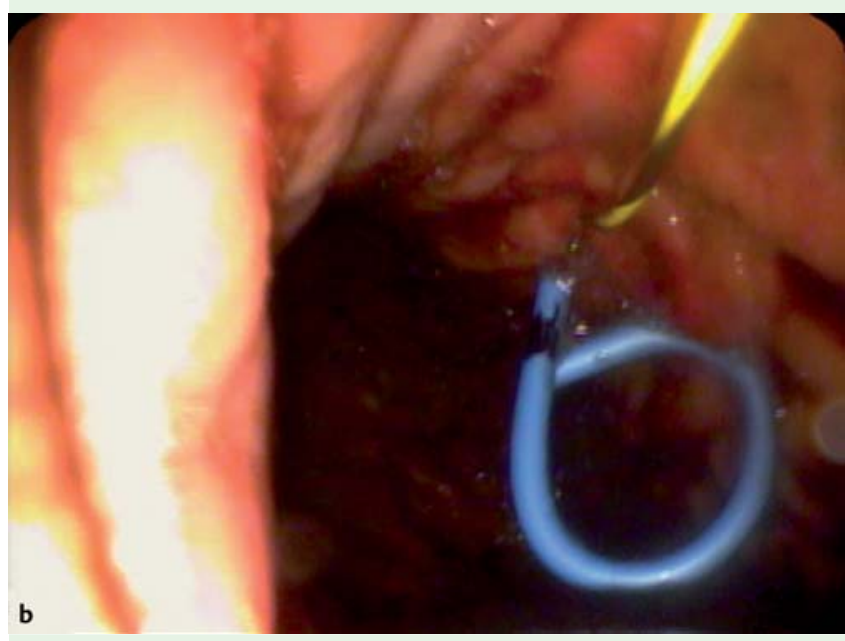

b A first double-pigtail stent was placed with the second wire already in place, followed (c) by placement of a second, similar stent.

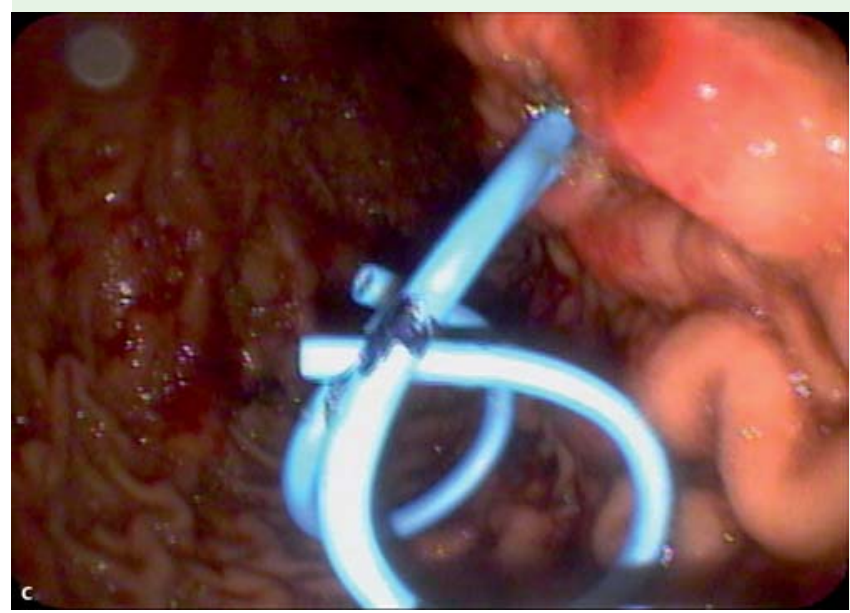




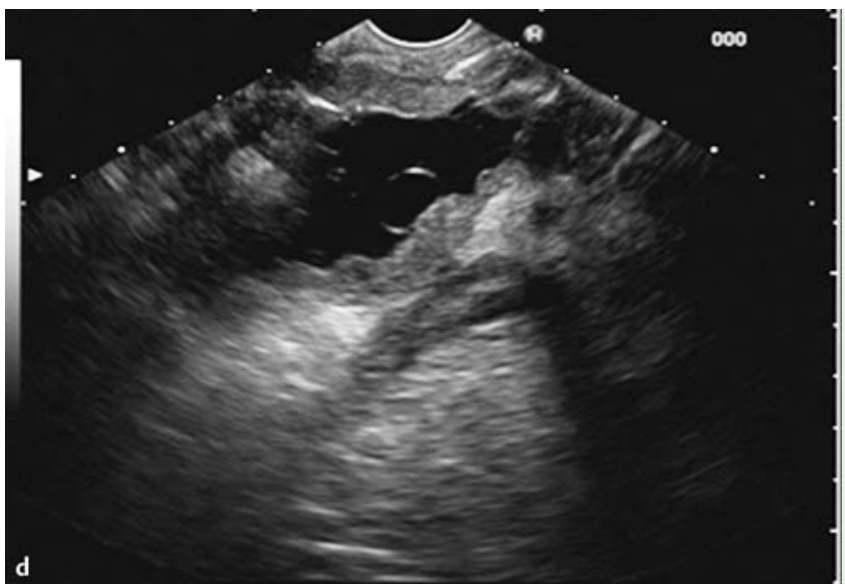

d At the end of the procedure, EUS showed partial collapse of the pseudocyst, with one of the double-pigtail stents showing in this cut.

could accommodate a 0.035 -inch guide wire. The modified catheter was subsequently advanced over the pre-positioned guide wire into the cyst cavity under endoscopic and fluoroscopic guidance. A second 0.035 -inch guide wire was placed through the second lumen into the cavity, followed by removal of the catheter, leaving two guide wires in place. One or two 7-Fr, 5-cm double-pigtail stents with or without a 7-Fr nasocystic catheter were placed over the guide wires ( Video 1 , - Fig. 1).
Endoscopy_UCTN_Code_TTT_1AS_2AD

M. A. Khashab, A. M. Lennon, V. K. Singh, E. J. Shin, M. I. Canto, A. N. Kalloo, P. I. Okolo III, S. A. Giday Division of Gastroenterology and Hepatology, Department of Medicine, The Johns Hopkins Medical Institutions, Baltimore, Maryland, USA

\section{Bibliography}

DOI $10.1055 / \mathrm{s}-0030-1255808$

Endoscopy 2010; 42: E292 -E293

(c) Georg Thieme Verlag KG Stuttgart - New York . ISSN 0013-726X

Corresponding author

S. A. Giday, MD

Johns Hopkins University

Division of Gastroenterology

1830 East Monument Street, Room 424

Baltimore

MD 21205

USA

sgiday1@jhmi.edu 